\title{
DEVELOPMENTAL STUDIES OF HETEROSIS AND NON-ALLELIC INTERACTIONS IN LOLIUM MULTIFLORUM
}

\author{
Y. A. EMARA* and K. J. R. EDWARDS† \\ Welsh Plant Breeding Station, Aberystwyth
}

Received 6.v.70

\section{INTRODUCTION}

Most of the genetic models used to estimate components of variation assume, among other assumptions, the absence of non-allelic interactions. In many cases this assumption may be invalid and needs to be tested if we are to get reliable estimates for the genetic components of variation (Lush, 1943; Mather, 1949; Comstock and Robinson, 1952).

Non-allelic interaction occurs where relative expression of different genotypes at any one locus is affected by the genic state at other loci. Many types of non-allelic interaction are known from studies of major Mendelian genes, such as complementary, epistatic and modifier genes. In continuous variation where the effects of individual genes cannot be studied, models and methods have been developed for detecting and estimating non-allelic interaction (Mather, 1949; Cockerham, 1954; Hayman, 1958; Jinks and Jones, 1958). Detection of such effects makes the picture of inheritance in polygenic systems more complicated than many simple biometrical genetic models assume.

One possible consequence of certain kinds of non-allelic interaction is heterosis, a phenomenon frequently observed in characters connected with reproductive capacity and physiological efficiency in outbreeding plants. Several genetic hypotheses have been put forward to explain heterosis and its converse, inbreeding depression. Davenport (1908), Bruce (1910) and Keeble and Pellew (1910) proposed the dominance hypothesis in which they suggest that heterosis is the result of accumulation of favourable dominants. The overdominance hypothesis was presented by East (1908) and Shull (1908), who suggested that heterosis is due to overdominance at single loci. In 1936 East restated the overdominance hypothesis in more modern genetic terminology to lead to the view that outbreeding mechanisms result from the physiological advantages of heterozygotes. The hypothesis supported by Mather (1943, 1956, 1960) and Dobzhansky and Wallace (1953) would reverse the causal sequence and make the physiological virtues in many heterozygotes the consequence of selection under an outbreeding system. Jinks (1954, 1955) and Jinks and Jones (1958) presented evidence suggesting that heterosis occurs with a higher frequency and greater magnitude in the presence of interactions between non-allelic genes brought together in the hybrid $F_{1}$. The argument continues and it seems very likely that no single hypothesis is the universal cause of heterosis.

The present paper reports a study which attempts to provide more information on the possible relations between heterosis and non-allelic inter-

* Present address: Department of Biology, Memorial University, St John's, Newfoundland, Canada.

$\uparrow$ Present address: Department of Genetics, Milton Road, Cambridge University. 
action. A number of developmentally related characters associated with leaf and tiller formation in Lolium multiflorum (Italian ryegrass) are compared. The use of developmental comparisons might help in an understanding of the physiological basis of any heterotic effects or non-allelic interactions. It has sometimes been claimed that a knowledge of the developmental basis of such effects can "explain away" interactions (Williams, 1959, but see Hayman, 1960). Williams attempted to make a distinction between "genetic" and "somatic" interactions, claiming that it was misleading to describe the latter, represented for example by the multiplicative relationship of components of fruit yield in tomato, as a genetic interaction. Hayman's reply pointed out that the distinction was made arbitrarily at a certain level of developmental organisation, and that it was possible to describe gene action and interaction only in relation to a specific character. Furthermore, this description would change according to the scale on which the character was measured. The choice of scale is also arbitrarily determined by the investigator for his convenience and the only real biological scale would be that relating the character to fitness. Bearing these limitations in mind, a knowledge of the developmental basis of a complex character may help in the study of relationships between non-allelic interaction and heterosis.

\section{Materials AND Methods}

Two selection lines were built from a commercial variety of Italian ryegrass derived originally from Northern Ireland. One line was selected for large area of sixth leaf on the main shoot while the other was selected for small area of the same leaf. Selection went on for five generations with a breeding population size of four in each generation. Thus, these lines should be fairly inbred, but may still segregate for some genes. However, even if there had been no selection, the proportion of those genes originally segregating which would have been expected to be fixed or lost by chance alone, due to small population size and assuming also no natural selection, would be substantial (Kimura, 1955). An $\mathrm{F}_{1}$ was derived from the two selection lines; then the seeds of $\mathrm{P}_{1}$ (large), $\mathrm{P}_{2}$ (small) along with their $\mathrm{F}_{1}$ were sown at the same time in boxes in a heated greenhouse in the autumn. Next spring the seedlings were potted up in 7-inch pots and a month later they were transferred outdoors. When the plants started heading they were moved back to the greenhouse for crossing. The method of automatic pollination technique without emasculation was adopted in carrying out the crosses (Jenkin, 193I) to get all generations, i.e. $\mathrm{P}_{1}, \mathrm{P}_{2}, \mathrm{~F}_{1}, \mathrm{~F}_{2}, \mathrm{~B}_{1}$ and $\mathrm{B}_{2}$, simultaneously, including new families of parental and $F_{1}$ generations. In every generation the four crosses were made reciprocally.

Seeds of the two reciprocal families of each of the four crosses of the six generations were sown in boxes in a heated greenhouse in the following autumn. The layout of the experiment consisted of four completely randomised blocks. Each family was represented by twelve plants giving a total of ninety-six plants for each of the six generations.

Fourteen characters covering many aspects of leaf development which included leaf dimensions, leaf production, tiller production and plant dry weight were studied. Details of methods of measurements was the same as those reported by Cooper (1959), Cooper and Edwards (196I) and Edwards and Cooper (1963). 
The following 14 characters were recorded:

Days to appearance of leaf 3 on main shoot.

Days to appearance of leaf 6 on main shoot.

Rate of appearance of leaves per day on main shoot between third and sixth leaves.

Length, width and area of leaf 3.

Length, width and area of leaf 6.

Tiller number per plant at third leaf stage.

Tiller number per plant at sixth leaf stage.

Tiller number per plant at 6 weeks.

Rate of tillering per day per plant between third and sixth leaf stages.

Dry weight of shoot at 3 months.

TABLE 1

Generation means and scaling test values far leaf dimensions

\begin{tabular}{|c|c|c|c|c|c|c|}
\hline \multirow[b]{2}{*}{ Item } & \multicolumn{3}{|c|}{ Third leaf } & \multicolumn{3}{|c|}{ Sixth leaf } \\
\hline & Length (mm.) & Width (mm.) & Area $\left(\mathrm{mm} .{ }^{2}\right)$ & Length (mm.) & Width (mm.) & Area $\left(\mathrm{mm} .{ }^{2}\right)$ \\
\hline $\begin{array}{l}\bar{P}_{1} \\
\bar{P}_{2} \\
\bar{F}_{1} \\
\bar{F}_{2} \\
\bar{B}_{1} \\
\bar{B}_{2}\end{array}$ & $\begin{array}{l}136 \cdot 6 \pm 1 \cdot 2 \\
121 \cdot 1 \pm 2 \cdot 3 \\
133 \cdot 5 \pm 4 \cdot 9 \\
131 \cdot 1 \pm 3 \cdot 1 \\
132 \cdot 5 \pm 4 \cdot 8 \\
124 \cdot 3 \pm 4 \cdot 0\end{array}$ & $\begin{array}{l}3 \cdot 19 \pm 0 \cdot 09 \\
2 \cdot 49 \pm 0 \cdot 06 \\
2 \cdot 92 \pm 0 \cdot 12 \\
2 \cdot 66 \pm 0 \cdot 08 \\
2 \cdot 81 \pm 0 \cdot 12 \\
2 \cdot 53 \pm 0 \cdot 07\end{array}$ & $\begin{array}{l}440 \cdot 4 \pm 12 \cdot 3 \\
304 \cdot 5 \pm 11 \cdot 8 \\
395 \cdot 8 \pm 29 \cdot 2 \\
351 \cdot 2 \pm 17 \cdot 4 \\
378 \cdot 3 \pm 27 \cdot 0 \\
319 \cdot 5 \pm 20 \cdot 6\end{array}$ & $\begin{array}{l}266 \cdot 6 \pm 10 \cdot 6 \\
192 \cdot 7 \pm 6 \cdot 2 \\
216 \cdot 3 \pm 10 \cdot 0 \\
217 \cdot 2 \pm 8 \cdot 3 \\
230 \cdot 1 \pm 6 \cdot 5 \\
183 \cdot 8 \pm 7 \cdot 0\end{array}$ & $\begin{array}{l}6 \cdot 10 \pm 0 \cdot 18 \\
4 \cdot 42 \pm 0 \cdot 10 \\
5 \cdot 30 \pm 0 \cdot 16 \\
4 \cdot 73 \pm 0 \cdot 11 \\
5 \cdot 04 \pm 0 \cdot 09 \\
4 \cdot 56 \pm 0 \cdot 06\end{array}$ & $\begin{array}{r}1658 \cdot 5 \pm 100 \cdot 8 \\
863 \cdot 1 \pm 43 \cdot 5 \\
1160 \cdot 0 \pm 81 \cdot 6 \\
1037 \cdot 9 \pm 56 \cdot 4 \\
1177 \cdot 3 \pm 48 \cdot 0 \\
849 \cdot 3 \pm 45 \cdot 2\end{array}$ \\
\hline $\begin{array}{l}\text { A } \\
\text { B } \\
\text { C }\end{array}$ & $\begin{array}{l}-5 \cdot 1 \pm 10 \cdot 8 \\
-5 \cdot 9 \pm 9 \cdot 8 \\
-6 \cdot 6 \pm 16 \cdot 2\end{array}$ & $\begin{array}{l}-0.48 \pm 0.28 \\
-0.34 \pm 0.23 \\
-0.89 \pm 0.41\end{array}$ & $\begin{array}{r}-79 \cdot 5 \pm 62 \cdot 7 \\
-61 \cdot 2 \pm 51 \cdot 8 \\
-131 \cdot 4 \pm 92 \cdot 3\end{array}$ & $\begin{array}{l}-22 \cdot 6 \pm 19 \cdot 6 \\
-41 \cdot 3 \pm 18 \cdot 3 \\
-23 \cdot 2 \pm 40 \cdot 5\end{array}$ & $\begin{array}{l}-1 \cdot 31 \pm 0.30^{* *} \\
-0.58 \pm 0 \cdot 22^{*} \\
-2 \cdot 19 \pm 0.59^{* *}\end{array}$ & $\begin{array}{l}-463 \cdot 9 \pm 161 \cdot 4^{*} \\
-324 \cdot 5 \pm 129 \cdot 3 \\
-690 \cdot 0 \pm 299 \cdot 4\end{array}$ \\
\hline
\end{tabular}

Non-allelic interactions in general were detected according to scaling tests devised for each particular generation (Mather, 1949) using the formulae:

\section{Scaling test}

$$
\begin{aligned}
& \mathrm{A}=2 \bar{B}_{1}-\bar{P}_{1}-\bar{F}_{1} \\
& \mathrm{~B}=2 \bar{B}_{2}-\bar{P}_{2}-\bar{F}_{1} \\
& \mathrm{C}=4 \bar{F}_{2}-2 \bar{F}_{1}-\bar{P}_{1}-\bar{P}_{2}
\end{aligned}
$$

Standard error of test

$$
\begin{aligned}
& \sqrt{4 V_{\bar{B}_{1}}+V_{P_{1}}+V_{F_{1}}} \\
& \sqrt{4 V_{\bar{B}_{2}}+V_{P_{2}}+V_{\bar{F}_{1}}} \\
& \sqrt{\overline{16} \bar{V}_{\bar{F}_{2}}+4 V_{F_{1}}+V_{P_{1}}+V_{P_{2}}}
\end{aligned}
$$

where $\bar{P}_{1}, \bar{P}_{2}$, etc., are means of each generation and $V_{P_{1}}, V_{\bar{P}_{2}}$, etc., are variances of family means of each generation.

In the absence of non-allelic interactions the scaling tests are expected to have a value of zero. Heterosis was detected by comparing the $F_{1}$ with both parents. These analyses, however, do not distinguish between overdominance and normal dominance.

\section{Results}

(a) Detection of non-allelic interaction

In table 1 the mean phenotypic values of third and sixth leaves dimensions along with their standard errors are shown for the two selection lines, 
$F_{1}, F_{2}$ and the two back-crosses. It is evident that there is no non-allelic interaction for third leaf dimensions, but by the sixth leaf stage non-allelic interactions emerge as $\mathrm{B}$ is significant, and $\mathrm{A}$ and $\mathrm{C}$ are highly significant for width, this being also reflected in the area where A and B are significant.

TABLE 2

Generation means and scaling test values for leaf appearance

\begin{tabular}{|c|c|c|c|}
\hline Item & $\begin{array}{l}\text { Days to } \\
\text { appearance of } \\
\text { third leaf }\end{array}$ & $\begin{array}{l}\text { Days to } \\
\text { appearance of } \\
\text { sixth leaf }\end{array}$ & $\begin{array}{l}\text { Rate of leaf } \\
\text { appearance } \\
\text { third to sixth leaf }\end{array}$ \\
\hline $\begin{array}{l}\bar{P}_{1} \\
\bar{P}_{2} \\
\bar{F}_{1} \\
\bar{F}_{2} \\
\bar{B}_{1} \\
\bar{B}_{2}\end{array}$ & $\begin{array}{l}42 \cdot 50 \pm 0 \cdot 57 \\
44 \cdot 57 \pm 0 \cdot 44 \\
41 \cdot 50 \pm 0 \cdot 54 \\
44 \cdot 21 \pm 0 \cdot 51 \\
43 \cdot 40 \pm 0 \cdot 51 \\
45 \cdot 10 \pm 0.36\end{array}$ & $\begin{array}{l}78 \cdot 09 \pm 0.85 \\
77 \cdot 90 \pm 0.43 \\
75 \cdot 18 \pm 0.58 \\
80.54 \pm 0.55 \\
79 \cdot 79 \pm 0.53 \\
79 \cdot 42 \pm 0.78\end{array}$ & $\begin{array}{l}0.084 \pm 0.0010 \\
0.089 \pm 0.0007 \\
0.089 \pm 0.0012 \\
0.082 \pm 0.0009 \\
0.082 \pm 0.0008 \\
0.087 \pm 0.0015\end{array}$ \\
\hline $\begin{array}{l}\text { A } \\
\text { B } \\
\text { C }\end{array}$ & $\begin{array}{l}2 \cdot 79 \pm 1 \cdot 33 \\
4 \cdot 14 \pm 1 \cdot 01 * * \\
6 \cdot 76 \pm 2 \cdot 41^{* *}\end{array}$ & $\begin{array}{c}6 \cdot 31 \pm 1 \cdot 48^{* *} \\
5 \cdot 76 \pm 1 \cdot 73^{*} \\
15 \cdot 82 \pm 2 \cdot 67 * *\end{array}$ & $\begin{array}{l}-0.009 \pm 0.00002^{* *} \\
-0.004 \pm 0.00005^{* *} \\
-0.023 \pm 0.00007 * *\end{array}$ \\
\hline
\end{tabular}

The results for leaf appearance characters are shown in table 2. Nonallelic interaction was detected for time of third leaf appearance, B and C being highly significant. At the sixth leaf stage non-allelic interaction appeared to be even more pronounced, as all of the three scaling tests were

TABle 3

Generation means and scaling test values for tiller production and dry weight

\begin{tabular}{|c|c|c|c|c|c|}
\hline Item & $\begin{array}{l}\text { Tiller number } \\
\text { at third leaf }\end{array}$ & $\begin{array}{l}\text { Tiller number } \\
\text { at sixth leaf }\end{array}$ & $\begin{array}{l}\text { Tiller number } \\
\text { at six weeks }\end{array}$ & $\begin{array}{l}\text { Rate of tillering } \\
\text { third to sixth leaf }\end{array}$ & $\begin{array}{l}\text { Dry weight } \\
\text { (mg.) }\end{array}$ \\
\hline $\begin{array}{l}P_{1} \\
\tilde{P}_{2} \\
\bar{F}_{1} \\
\bar{F}_{2} \\
\bar{B}_{1} \\
\bar{B}_{2}\end{array}$ & $\begin{array}{l}1 \cdot 31 \pm 0.08 \\
1 \cdot 15 \pm 0.05 \\
1 \cdot 58 \pm 0.08 \\
1 \cdot 52 \pm 0.04 \\
1 \cdot 50 \pm 0 \cdot 10 \\
1 \cdot 43 \pm 0.09\end{array}$ & $\begin{array}{l}4 \cdot 70 \pm 0 \cdot 38 \\
4 \cdot 85 \pm 0 \cdot 25 \\
6 \cdot 90 \pm 0 \cdot 31 \\
7 \cdot 74 \pm 0 \cdot 43 \\
7 \cdot 32 \pm 0 \cdot 58 \\
7 \cdot 61 \pm 0 \cdot 53\end{array}$ & $\begin{array}{l}2 \cdot 18 \pm 0 \cdot 16 \\
2 \cdot 30 \pm 0 \cdot 12 \\
2 \cdot 81 \pm 0 \cdot 13 \\
2 \cdot 60 \pm 0 \cdot 05 \\
2 \cdot 53 \pm 0 \cdot 14 \\
2 \cdot 59 \pm 0 \cdot 13\end{array}$ & $\begin{array}{l}0 \cdot 093 \pm 0 \cdot 008 \\
0 \cdot 111 \pm 0 \cdot 007 \\
0 \cdot 157 \pm 0 \cdot 007 \\
0 \cdot 169 \pm 0 \cdot 011 \\
0 \cdot 159 \pm 0 \cdot 012 \\
0 \cdot 178 \pm 0 \cdot 012\end{array}$ & $\begin{array}{l}419 \cdot 76 \pm 19 \cdot 57 \\
233 \cdot 48 \pm 11 \cdot 65 \\
502 \cdot 12 \pm 38 \cdot 75 \\
327 \cdot 67 \pm 29 \cdot 22 \\
383 \cdot 36 \pm 35 \cdot 35 \\
276 \cdot 62 \pm 20 \cdot 33\end{array}$ \\
\hline $\begin{array}{l}\text { A } \\
\text { B } \\
\text { C }\end{array}$ & $\begin{array}{l}0 \cdot 10 \pm 0 \cdot 22 \\
0 \cdot 13 \pm 0 \cdot 21 \\
0 \cdot 46 \pm 0 \cdot 24\end{array}$ & $\begin{array}{l}3 \cdot 05 \pm 1 \cdot 26 * \\
3 \cdot 48 \pm 1 \cdot 13^{*} \\
7 \cdot 62 \pm 1 \cdot 89 * *\end{array}$ & $\begin{array}{l}0 \cdot 07 \pm 0.34 \\
0 \cdot 07 \pm 0.32 \\
0 \cdot 31 \pm 0.39\end{array}$ & $\begin{array}{l}0 \cdot 068 \pm 0 \cdot 026^{*} \\
0 \cdot 088 \pm 0 \cdot 022^{* *} \\
0 \cdot 158 \pm 0 \cdot 042^{* *}\end{array}$ & $\begin{array}{l}-155 \cdot 16 \pm 82 \cdot 96 \\
-182 \cdot 35 \pm 57 \cdot 36^{*} \\
-346 \cdot 82 \pm 142 \cdot 08^{*}\end{array}$ \\
\hline
\end{tabular}

significant or highly significant. For rate of leaf appearance between third and sixth leaves the three scaling tests were highly significant.

Table 3 shows the results of tiller number at third and sixth leaf stages, tiller number at six weeks from sowing, rate of tillering and dry weight. Whereas no non-allelic interaction was detected in tiller number at third leaf stage or after six weeks from sowing, tiller number at the sixth leaf stage and rate of tillering between third and sixth leaves showed significant nonallelic interaction. Dry weight showed non-allelic interaction as B and C were both significant. 
Now, it appears in general that non-allelic interaction has no significant role in the early stages of development, but during later stages of development a complex situation emerges and genes at different loci start interacting. Thus, there appears to be no detectable non-allelic interactions at the third leaf stage, but at the sixth leaf stage and later on, evidence for non-allelic interaction start to accumulate.

\section{(b) Detection of heterosis}

Examination of the means of the two selection lines and their $F_{1}$ in tables 1,2 and 3 shows that in all leaf dimensions the $F_{1}$ is intermediate between $\mathrm{P}_{1}$ and $\mathrm{P}_{2}$ which means that these characters do not exhibit heterosis.

There is no significant heterosis for rate of leaf appearance. But at the sixth leaf stage the parental line which was the earlier at the third leaf stage $\left(P_{1}\right)$ has become the later as a result of a slower rate of leaf appearance than either $P_{2}$ or $F_{1}$. This means that heterosis is now measured as the difference between the means of $F_{1}$ and $P_{2}$, a difference which is significant.

Table 3 shows that there is significant heterosis for all tiller and dry weight characters, the $F_{1}$ having more tillers and greater weight than either parent.

\section{Discussion}

These studies show that non-allelic interactions, as detected by scaling tests, became much more evident at later stages of development: for example, sixth leaf dimensions show some interactions whereas third leaf do not, and later aspects of tillering give significant deviations in the scaling tests. A simple, if perhaps naive, view of this situation is that the later a gene acts in the development of a character complex the more likely it is that its expression will be influenced by action of earlier genes. Heterosis shows a similar trend, becoming more pronounced as development proceeds for rate of leaf appearance but is present for all recorded stages of tiller development and not at all for leaf size. This phenomenon of changing gene-action during development has been demonstrated by Jinks and Broadhurst (1963) in a study of body weight in rats. They suggest that the change they detected is due either to different loci controlling the character at different stages of development or, alternatively, the same loci are always in control but the dominance relationships of their alleles change with development; presumably, in the present study we may add to this the change of epistatic relationships between loci with development.

In table 4 the characters are classified according to the presence or absence of detectable non-allelic interaction and heterosis. The detection of non-allelic interactions by individual scaling tests is a somewhat crude technique, and not all types of interaction are likely to give rise to heterosis. Nevertheless, of the six characters which show heterosis, four produced detectable interactions while the other two did not. This suggests that while non-allelic interactions may be a cause of heterosis in some characters they are not in all.

Let us now see how a consideration of the developmental relationships of the characters can amplify this association. The most interesting complexes are those concerned with leaf appearance and tiller formation, since leaf dimensions show no heterosis and little interaction. 
Variation in the number of days to reach a particular stage of leaf appearance will depend on: (i) differences in the start of development, that is germination; and (ii) variation in the rate of leaf appearance thereafter. Data on germination time were not collected and the earliest available character is appearance of leaf 3 . Here $\mathrm{P}_{2}$ is significantly later than $\mathrm{P}_{1}$, the $\mathrm{F}_{1}$ mean being not significantly different from the latter parent. The rate of leaf appearance between this stage and the appearance of leaf 6 shows that $P_{1}$ is significantly slower than both $P_{2}$ and $F_{1}$ which have the same value. Thus by the sixth leaf stage the two parental lines do not differ because the two compensating processes have cancelled each other out; but the $\mathbf{F}_{\mathbf{1}}$ is now significantly heterotic having been like the faster parent for both processes. Thus the accumulation of favourable dominants could explain this heterosis although the situation is complicated by the presence of non-allelic interactions for both characters.

TABLE 4

The association between non-allelic interaction and heterosis

\begin{tabular}{|c|c|c|c|}
\hline $\begin{array}{l}\text { No interaction, } \\
\text { no heterosis }\end{array}$ & $\begin{array}{l}\text { No interaction, } \\
\text { heterosis }\end{array}$ & $\begin{array}{l}\text { Interaction, } \\
\text { no heterosis }\end{array}$ & $\begin{array}{l}\text { Interaction, } \\
\text { heterosis }\end{array}$ \\
\hline Third leaf length & $\begin{array}{l}\text { Tiller number at } \\
\text { third leaf }\end{array}$ & Sixth leaf width & Appearance of leaf 6 \\
\hline Third leaf width & $\begin{array}{l}\text { Tiller number at } \\
6 \text { weeks }\end{array}$ & Sixth leaf area & Rate of tillering \\
\hline Third leaf area & & $\begin{array}{l}\text { Rate of leaf } \\
\text { appearance }\end{array}$ & $\begin{array}{l}\text { Tiller number at } \\
\text { sixth leaf }\end{array}$ \\
\hline Sixth leaf length & & Appearance of leaf 3 & Dry weight of shoot \\
\hline
\end{tabular}

This particular character complex demonstrates the danger of assuming that inheritance below any arbitrary level in the heirarchy of developmental relations in a complex character will necessarily be simpler and less likely to show interactions. The two component characters, days to leaf 3 and rate of leaf appearance thereafter, appear to combine additively to give the time to leaf 6 , and yet individually each shows evidence of non-allelic interaction.

Turning to tillering characters, similar arguments to those developed for leaf appearance can be advanced, except that the developmental situation is more complex. In addition to effects of germination time and rate of tillering, the tiller number at any given time or stage is likely to be influenced by variation in the onset of tillering since this may begin in the axil of either the coleoptile or of leaf 1 . This difference can lead to very large differences in later tiller number. Heterosis is present for the earliest recorded tillering characteristic, the tiller number per plant at the third leaf stage, although the two parental lines do not differ significantly. If it is correct that $P_{1}$ was the faster germinating of the two parents, and if $\mathrm{P}_{2}$ began tillering at a lower node, then a heterotic situation could arise if the $F_{1}$ showed dominance (potence) for both characters. This argument is largely speculative, but not entirely so for Edwards (1961) showed that differences between these two parental lines did exist in the required direction for position of onset of tillering. The interpretation of the accumulation of favourable dominants is further supported by the absence of non-allelic interaction for this character.

Tiller number at 6 weeks shows a basically similar pattern to that at the third leaf stage except that the ranking of parental lines has changed. This is presumably a reflection of the faster rate of leaf appearance in $\mathrm{P}_{2}$ which will therefore have produced more leaves than $\mathrm{P}_{1}$ at six weeks. 
The rate of tillering per plant between the third and sixth leaves shows both interaction and heterosis, which are both present for tiller number at the sixth leaf stage also. Interpretation of the rate of tillering is difficult because of the developmental complexity of the process. The rate tends to be exponential in seedlings because each new tiller produces more sites at which further tillering may occur. Thus if the $F_{1}$ is already superior to both parental lines in tiller number at the third leaf stage, this heterosis is likely to be increased as tillering proceeds. It seems likely that non-allelic interactions, possibly of a multiplicative nature, will be important in determining heterosis for this character.

Finally, dry weight per shoot also shows both non-allelic interactions and heterosis. Since shoot weight will depend upon both tiller number and tiller size, the latter being in turn determined largely by leaf size and leaf number per tiller, it seems likely that it will show complex interactions which may well explain the heterosis. The two parental lines differ in shoot weight, the line selected for large leaves $\left(P_{1}\right)$ being heavier. These lines differed only little in tiller number or rate of leaf appearance and the differences in shoot weight are presumably a consequence of changes in leaf size.

Thus the developmental analysis also points to the view that heterosis in some characters may be due to accumulation of favourable dominants while in others non-allelic interaction may be important. It does, however, suggest that the non-allelic interaction detected for certain characters, such as time to leaf six and tiller number at the sixth leaf stage, may not be important in producing the heterosis shown for these characters. In this material it would appear that non-allelic interaction is more likely to be involved in heterosis later in development of a character complex.

The existence of marked heterosis for shoot dry weight suggests the possibility of exploiting this in a breeding programme, and if this is to be done a knowledge of the genetic basis of the heterosis is extremely valuable. Unfortunately no adequate control was available because the seed of the original population from which the two selection lines had been derived had become inviable by the end of the selection programme. Certainly in the early stages of selection both lines showed a marked decline in shoot weight compared with the base population (Edwards, 196I) and so the heterosis may be no more than a recovery towards the original level. Furthermore, ryegrass, because of its breeding system and because it is not a high value cash crop hardly seems a likely candidate for a breeding programme leading to a hybrid variety.

Finally, the frequent occurrence of detectablenon-allelic interactionsin this group of characters associated with early stages of development, together with the evidence that such interactions become more common later in development, points again to the dangers of assuming that such interactions are absent in producing models for the study of the inheritance of continuous variation.

\section{Summary}

1. From two lines of Lolium multiflorum selected for large and small leaf size respectively, the $F_{1}, F_{2}$ and two back-cross were derived. The six generations were grown simultaneously and compared for a number of developmentally related characters associated with leaf dimensions, leaf appearance, tillering and shoot weight. 
2. From the generation means heterosis and non-allelic interactions were studied.

3. Non-allelic interactions tended to be more frequent at later stages of development, whereas heterosis was present for all five characters associated with tillering or weight, but only for one of the nine characters representing leaf dimensions or leaf complexes.

4. Of the six characters exhibiting heterosis, four also showed non-allelic interactions.

5. A consideration of the developmental relationships of these characters suggested that heterosis at early stages of development is likely to be due to the accumulation of dominant genes, whereas at later stages non-allelic interaction may be an important component also.

\section{REFERENCES}

BRUCE, A. B. 1910. The Mendelian theory of heredity and the augmentation of vigor. Science, 32, 627-628.

COCKERHAM, G. c. 1954. An extension of the concept of partitioning hereditary variance for analysis of covariance among relatives when epistasis is present. Genetics, 39, 859-882. COMSTOCK, R. E., AND ROBINSON, H. F. 1952. Estimation of average dominance of genes. In Heterosis (ed. J. W. Gowen), pp. 494-516. Ames, Iowa State College Press.

COOPER, J. P. 1959. Selection and population structure in Lolium II-Genetic control of date of ear emergence. Heredity, 13, 445-459.

COOPER, J. P., AND EDWARDS, K. J. R. 1961. The genetic control of leaf development in Lolium. I. Assessment of genetic variation. Heredity, 16, 63-82.

DAVENPORT, C. B. 1908. Degeneration, albinism and inbreeding. Science, 28, 455-455.

DOBzhansky, th., and wallace, в. 1953. The genetics of homeostasis in Drosophila. Proc. Natl. Acad. Sci. U.S.A., 39, 162-171.

EAST, E. M. 1908. Inbreeding in corn. Rep. Conn. Agric. Exp. Sta. for 1907, 419-428.

EAST, Е. м. 1936. Heterosis. Genetics, 21, 375-397.

EDWARDS, K. J. R. 1961. Genetic control of leaf and tiller development in grasses. Ph.D. Thesis, University of Wales (unpublished).

EDWARDS, K. J. R., AND COOPER, J. P. 1963. The genetic control of leaf development in Lolium. II. Response to selection. Heredity, 18, 307-317.

HAYMAN, B. 1. 1958. The separation of epistatic from additive and dominance variations in generation means. Heredity, 21, 371-390.

hayman, в. 1. 1960. Heterosis and quantitative inheritance. Heredity, 15, 324-327.

JENKIN, T. J. 1931. The method and technique of selection, breeding and strain-building in grasses. Bull. Bur. Pl. Gen., Aberystwyth, 3, 5-34.

jinks. J. L. 1954. The genetical basis of heterosis. Maize Gen. Coop. Newes Let., 28, 47-50.

JINKS, J. L. 1955. A survey of the genetical basis of heterosis in a variety of diallel crosses. Heredity, 9, 223-238.

JINKS, J. L., AND BROADHURST, P. L. 1963. Diallel analysis of litter size and body weight in rats. Heredity, 18, 319-336.

JINKS, J. L., AND JONES, R. M. 1958. Estimation of the components of heterosis. Genetics, 43, 223-234.

KEEBLE, F., AND PELLEW, C. 1910. The mode of inheritance of stature and of time of flowering in peas (Pisum sativum). Four. Genetics, 1, 47-56.

KIMURA, M. 1955. Solution of a process of random genetic drift with a continuous model. Proc. Natl. Acad. Sci. U.S.A., 41, 144-150.

Lush, J. L. 1943. Animal breeding plans, 2nd edition, pp. 76-79. The Collegiate Press Inc., Ames, Iowa.

MATHER, K. 1943. Polygenic inheritance and natural selection. Biol. Revs., 18, 32-64.

Mather, K. 1949. Biometrical Genetics. Methuen, London.

Mather, K. 1956. Response to selection. Cold Spring Harbor Symp. Quant. Biol., 20, 158-165.

Mather, K. 1960. Evolution in polygenic systems. Evoluzione e Genetica, Accademia Nazionale dei Lincei, Qud., 47, 131-152.

shull, G. н. 1908. The composition of a field of maize. Rep. Amer. Breed. Ass., 4, $296-301$. williams, w. 1959. Heterosis and the genetics of complex characters. Nature, 184, 527. 